\author{
SoTEL Symposium 19-20 February 2020
}

\title{
Exploring case based clinical learning in graduate-entry nursing
}

\author{
Rachel Macdiarmid \\ Auckland University of Technology \\ rachel.macdiarmid@aut.ac.nz \\ Rhona Winnington \\ Auckland University of Technology \\ rhona.winnington@aut.ac.nz \\ Eamon Merrick \\ Auckland University of Technology \\ eamon.merrick@aut.ac.nz
}

Submission Type: Case study (20mins +10 minsQ\&A)

Keywords: Graduate-entry nursing, educational design research, technology enhanced learning

\section{Abstract:}

The Master of Nursing Science (MNSc) has been developed as a Graduate Entry to Nursing (GEN) programme. It is an accelerated, intensive two-year degree involving the completion of 1100 clinical practice hours to meet New Zealand Nursing Council registration requirements, together with achieving a level of critical thinking that will support excellence in clinical practice. GEN programmes are well known to attract diverse, motivated graduates often with successful careers that want a change of direction (Stacey, Pollock \& Crawford, 2016; Pellico, Terrill, White \& Rico, 2012).

In 2019 the MNSc was in its first iteration, therefore the three lecturers involved had scope to consider the design and delivery of the learning to best support student understanding and engagement. Together with institutional teaching and learning development mentors we brainstormed different approaches to teaching and learning. There is dearth of evidence regarding the development of clinical reasoning and critical thinking for post-graduate nursing students in Australasia. The aim was to develop teaching approaches that encouraged students to engage with the content and foster the development of critical thinking and clinical reasoning. Meyers and Nulty's (2009) adoption of Biggs (2003) 3P Model of learning and teaching influenced the development of content across multiple discrete units of study. An evolving case study approach supported with podcasts was developed. The first evolving case study focused on a client with a rural New Zealand address and health status common to his age group and life experience. The podcasts aligned with the weekly development of the case. International content experts participated in topics as varied the management of analgesia, history of consent, and assisted dying and others.

To iteratively explore and understand the effectiveness of this teaching approach the authors concurrently undertook research. Informed by educational design research (EDR) methodology we explore the process of constructing an authentic learning experience for students. Educational design research (EDR) evolved from design-based research and is recognised as being practical and eminently suitable to explore a small teaching and learning project (Jetinikoff, 2015; McKenney \& Reeves, 2018). The aims of this research were to 1) explore and describe the process of constructing an authentic learning experience enabled by technology; and 2) understand and reflect on student learning using an evolving case-study with podcasted content. The research team is currently undertaking the reflection, adaption, and evaluation stage of the EDR methodology. The results of this and the theory stage will be resented at SoTEL. In this presentation, the analysis of the teaching teams' reflections will be explored. Key to our discussion with the audience will be sharing our reflections and in turn seeking their advice to explore how to engage students in technology enhanced delivery in a fast-paced course. 


\section{References:}

Biggs, J.B. (2003). Teaching for quality learning at university. (2nd ed.). Maidenhead: Open University Press.

Jetnikoff, A. (2015). Design based research methodology for teaching with technology in English. English in Australia, 50(3), 56-60.

McKenney, S., \& Reeves, T. (2018). Conducting Educational Design Research ( ${ }^{\text {nd }}$ ed.). Routledge: https://ebookcentral.proquest.com/lib

Meyers, N. M., \& Nulty, D. D. (2009). How to use (five) curriculum design principles to align authentic learning environments, assessment, students approaches to thinking and learning outcomes. Assessment \& Evaluation in Higher Education, 34, (5), 565-577.

Pellico, L.H., Terrill, E., White, P., \& Rico, J. (2012). Integrative review of graduate entry programs. Journal of Nursing Education, 51(1), 29-37. http://dx.doi:10.3928/01484834-20111130-01.

Stacey, G. Pollock, K., \& Crawford, P. (2016). The rules of the game in graduate entry nursing: A longitudinal study. Nurse Education Today, 36, 184-189. http://dx.doi:10.org/10/1016/j.nedt.2015.09.016 